\title{
Frequency and Site of Skeletal Metastatic Lesion Detected by Bone Scintigraphy in Newly Diagnosed Asymptomatic Cancer Patients
}

Taslima Sifat, Fatima Begum, Sadia Sultana, Pupree Mutsuddy, Afroza Naznin and Shamim M F Begum

National Institute of Nuclear Medicine and Allied Sciences (NINMAS), Dhaka, Bangladesh

Correspondence Address : Dr. Taslima Sifat, M Phil (Nuclear Medicine) student, National Institute of Nuclear Medicine \& Allied Sciences (NINMAS), Email: sifat.mmc2010@gmail.com

\begin{abstract}
Objectives: Bone is one of the most common organ for metastasis. Bone scintigraphy is widely used for staging of cancer patients before initiation of chemotherapy and adjuvant therapy and it can detect both symptomatic and asymptomatic bone metastases. The purpose of this study was to determine the frequency and site of metastatic bone lesion detected by bone scintigraphy in newly diagnosed asymptomatic cancer patients who werwe referred to National Institute of Nuclear Medicine \& Allied Sciences (NINMAS) for bone scintigraphy.

Patients and Methods: This cross sectional observational type of study was carried out in NINMAS from July 2015 to June 2016. A total of $\mathbf{1 1 6}$ newly diagnosed asymptomatic cancer patients referred for the first time bone scintigraphy were included in this study.

Results: Of the total 116 patients ( 57 male and 59 female; mean age: $54.8 \pm 14.0$ years), $46(39.7 \%)$ patients had carcinoma breast, 30 (25.9\%) patients had carcinoma prostate, $12(10.3 \%)$ patients had carcinoma lung, 8(6.9\%) patients had carcinoma urinary bladder, 4(3.4\%) patients had renal cell carcinoma and $16(13.8 \%)$ patients had other cancer. Bone scan was found positive for metastatic disease in $\mathbf{4 4 . 8 \%}$ patients. Most common sites of bone metastases in different types of cancer in newly diagnosed asymptomatic cancer patients were rib, then hip bone, vertebral column (lumbar vertebra, thoracic vertebra respectively), sternum and skull.

Conclusion: In this study, it was revealed that newly diagnosed asymptomatic cancer patients are frequently associated with metastatic bone disease, those can be detected by bone scintigraphy.

Key words: Bone Scintigraphy, Asymptomatic cancer patients.
\end{abstract}

\section{INTRODUCTION}

Cancer is an important cause of morbidity and mortality in Bangladesh. The estimated incidence of 12.7 million new cancer cases worldwide in 2008 will rise to 21.4 million by 2030 (1). Metastases to bone is common than primary bone malignancies and it is the third most common organ affected by metastasis, after the lungs and liver (2). Almost all types of cancer may metastasize to bone. But metastases from carcinomas are the most common, particularly those arising in the following areas- breast, lung, prostate, kidney, thyroid (3).

Bone metastases most commonly affect the axial skeleton, which contains the red marrow in the adult. The vertebrae, pelvis, ribs and the ends of long bones are most common sites of metastases because of their high red marrow content. Within the spine, $52 \%$ metastases are located in the lumbar spine, $36 \%$ are located in the thoracic spine and $12 \%$ are located in the cervical spine. Mandible, patella and distal extremities are the less frequent metastatic sites (2).

Many metastatic bone lesions cause no symptom. The presentation of metastatic bone disease is variable, but pain is the most common complaint. Other clinical feature includes- hypocalcaemia, pathological fracture and neurological symptoms due to compression of the spinal cord or cauda equine and spinal instability. Complication of bone metastases are referred as "skeletal related events". The occurrence of these morbid events is not regular, and becoming more frequent as the disease becomes more extensive and the treatment options reduce (4). Therefore, early detection of bone metastases is essential for (i) accurate staging and optimal treatment; and (ii) to allow selecting suitable treatment strategies to reduce the risk of complications and improve quality of life (2). 
In NINMAS, bone scintigraphy is being done for decades. A good number of cancer patients are sent to NINMAS by the clinicians for bone scintigraphy for baseline staging and follow up. But sometimes asymptomatic cancer patients may remain undiagnosed due to social condition and lack of widespread facility. In this regard, more care needs to be taken for diagnostic procedure for the sake of the wellbeing of the patients, especially the asymptomatic cancer patients. Only a few studies have been undertaken in this institute prospectively to evaluate the role of bone scintigraphy in newly diagnosed asymptomatic cancer patients. Therefore, this prospective observational study was designed to assess the utility of bone scintigraphy in detecting metastases in newly diagnosed cancer patients as baseline investigation, who were asymptomatic for bone metastases.

\section{PATIENTS AND METHODS}

This cross sectional observational type of study was carried out at NINMAS, BSMMU campus, Dhaka during the period of July 2015 to June 2016. Newly diagnosed asymptomatic cancer patients referred to the institute (NINMAS) for the first time bone scan were included in this study. A total of 116 patients were enrolled in this study. All the patients were informed of the potential risks and benefit of the procedure and informed consent was taken from each individual case before inclusion in the study. Details of the history were obtained on the data collection sheet.

Bone scintigraphy was performed with 99mTc Methylene diphosphonate (MDP) given intravenously at a dose of 555-740MBq (15-20 m Ci). Imaging was done 2-3 hours after tracer injection by a dual head gamma camera using low energy, high resolution collimator. The whole body bone scanning was accomplished by obtaining anterior and posterior views. Additional views were taken where necessary to define the location and extent of any questionable abnormality. Interpretation done by experienced nuclear medicine physician and abnormalities (area of increased or decreased tracer localization) were recorded according to number, anatomical location and distribution (focal or diffuse). Bone biopsy, the confirmatory investigation for bone metastases, was not done due to unavailability and the skeletal lesions were considered as metastatic and non-metastatic according to the opinion of nuclear medicine experts.

The collected data were compiled and analyzed using window based computer software MS Excel and Statistical Package for Social Sciences (SPSS16) by appropriate statistical methods. Continuous data were presented as mean and standard deviation (SD). Categorical/qualitative data were presented as percentage $(\%)$. Chi-Square test was used to analyze the variable. Level of significance was 0.05 and pvalue $\leq 0.05$ was considered as significant. Various tables were used for data presentation.

\section{RESULTS}

Total 116 patients (M-57, F-59) age ranging from 2089 years (mean $\pm \mathrm{SD}=54.8 \pm 14$ years) were included (Table 1). Majority (39.7\%) patients had breast cancer followed by $30(25.9 \%)$ prostate cancer patients, 12 $(10.3 \%)$ lung cancer patients, $8(6.9 \%)$ urinary bladder cancer patients, $4(3.4 \%)$ renal cancer patients and $16(13.8 \%$ ) miscellaneous cancer patients (Table 2).

Table 1: Distribution of the study subjects by sex and age ( $n=116)$

\begin{tabular}{lll}
\hline $\begin{array}{l}\text { Demographic } \\
\text { Variable }\end{array}$ & $\begin{array}{l}\text { Number of patients } \\
(\mathbf{n = 1 1 6})\end{array}$ & $\begin{array}{l}\text { Percentage } \\
\mathbf{( \% )}\end{array}$ \\
\hline Sex & & \\
Male & 57 & 49.1 \\
Female & 59 & 50.9 \\
Age & Mean \pm SD & Range \\
& (in years) & (in years) \\
& $54.8 \pm 14.0$ & $20-89$ \\
\hline
\end{tabular}

Table 2: Distribution of the study subjects by type of cancer $(n=116)$

\begin{tabular}{lcc}
\hline & $\begin{array}{c}\text { Number of patients } \\
(\mathbf{n}=\mathbf{1 1 6})\end{array}$ & $\begin{array}{c}\text { Percentage } \\
\mathbf{( \% )}\end{array}$ \\
\hline Breast & 46 & 39.7 \\
Prostatc & 30 & 25.9 \\
Lung & 12 & 10.3 \\
Urinary bladder & 8 & 6.9 \\
Kidney & 4 & 3.4 \\
Other & 16 & 13.8 \\
\hline
\end{tabular}

Out of 116 patients 52(44.8\%) cases were reported by expert nuclear medicine physicians as positive for metastatic lesions and 64(55.2\%) negative for 
metastatic lesions (Table 3). Among 52 cases of bone scans positive for metastases, $41(78.8 \%)$ had multiple skeletal metastatic lesions, whereas, solitary skeletal metastatic lesion was found in 11(21.2\%) (Table 4).

Table 3: Distribution of the study subjects according to bone scan findings $(n=116)$

\begin{tabular}{lll}
\hline $\begin{array}{l}\text { Bone scan findings } \\
\text { for metastatic lesions }\end{array}$ & $\begin{array}{l}\text { Number of patients } \\
(\mathbf{n = 1 1 6 )}\end{array}$ & $\begin{array}{l}\text { Percentage } \\
(\mathbf{\%})\end{array}$ \\
\hline Positive & 52 & 44.8 \\
Negative & 64 & 55.2 \\
\hline
\end{tabular}

Table 4: Distribution of the study subjects according to number of skeletal metastatic lesions $(n=52)$

\begin{tabular}{|c|c|c|}
\hline metastatic lesions & $\begin{array}{l}\text { Number of patients } \\
(\mathrm{n}=52)\end{array}$ & $\begin{array}{l}\text { Percentage } \\
(\%)\end{array}$ \\
\hline Solitary & 11 & 21.2 \\
\hline Multiple & 41 & 78.8 \\
\hline
\end{tabular}

Among the 52 patients, majority $(57.7 \%)$ patients had rib as metastatic site. Hip bone and lumbar vertebra had same frequency $(32.7 \%)$ as metastatic site. Fourteen $(26.9 \%)$ patients had thoracic vertebra as metastatic site (Table 5).

Table 5: Site of skeletal metastatic lesions in study subjects including data of multiple sites involvement in same patients $(n=52)$

\begin{tabular}{lll}
\hline & $\begin{array}{l}\text { Number of patients } \\
(\mathbf{n = 5 2})\end{array}$ & $\begin{array}{l}\text { Percentage } \\
(\mathbf{\%})\end{array}$ \\
\hline Rib & 30 & 57.7 \\
Ilip bonc & 17 & 32.7 \\
Lumbar vertebra & 17 & 32.7 \\
Thoracic vertebra & 14 & 26.9 \\
Sternum & 12 & 23.1 \\
Skull & 12 & 23.1 \\
Sacrum & 9 & 17.3 \\
Cervical vertebra & 8 & 15.4 \\
Proximal femur & 7 & 13.5 \\
Distal femur & 5 & 9.6 \\
Proximal humerus & 4 & 7.7 \\
Distal humerus & 3 & 5.8 \\
Scapula & 2 & 3.8 \\
Clavicle & 1 & 1.9 \\
\hline
\end{tabular}

Among carcinoma breast patients, 10(21.7\%) had positive bone scan and 36(78.3\%) had negative bone scan. Among the carcinoma prostate patients,
20(66.7\%) had positive bone scan and 10(33.3\%) had negative bone scan. Carcinoma prostate and carcinoma breast had significantly $(\mathrm{P}<0.05)$ higher and significantly $(\mathrm{P}<0.05)$ lower positive bone scan findings, respectively (Table 6).

Table 6: Distribution of the study subjects according to bone scan findings in different cancers $(n=116)$

\begin{tabular}{lllll}
\hline Type of cancer & $\begin{array}{l}\text { Number of } \\
\text { patients } \\
(\mathbf{n = 1 1 6 )}\end{array}$ & $\begin{array}{l}\text { Bone scan findings } \\
\text { Positive } \\
(\mathbf{n = 5 2 )}\end{array}$ & $\begin{array}{l}\text { Negative } \\
(\mathbf{n = 6 4 )} \\
\mathbf{n ( \% )}\end{array}$ & $\mathbf{n}(\mathbf{\%})$ \\
\hline Breast & 46 & $10(21.7)$ & $36(78.3)$ & 0.001 \\
Prostate & 30 & $20(66.7)$ & $10(33.3)$ & 0.005 \\
Lung & 12 & $8(66.7)$ & $4(33.3)$ & 0.108 \\
Urinary bladdcr & 8 & $5(62.5)$ & $3(37.5)$ & 0.298 \\
Kidney & 4 & $3(75.0)$ & $1(25.0)$ & 0.217 \\
Other & 16 & $6(37.5)$ & $10(62.5)$ & 0.526 \\
\hline
\end{tabular}

Level of significance 0.05

$P$ value was calculated from chi square test

\section{DISCUSSION}

Bone scintigraphy can detect both symptomatic and asymptomatic bone metastases. Love, et al. (2003) reported that about $75 \%$ of patients with malignancy and pain have abnormal bone scintigraphic findings. Perhaps even more importantly, 25\%-45\% of asymptomatic cancer patients have scintigraphic evidence of bone metastases (5). In this present study it was observed that $44.8 \%$ asymptomatic cancer patients were found to have positive metastatic lesions on bone scan. This study finding differ from study done by Embati (2015), who found $81.6 \%$ metastatic lesions in symptomatic patients and $88.9 \%$ in asymptomatic patients (6). This discordance may be due to the total number of patients $(\mathrm{n}=1575)$ in his study. Moreover, he included all types of cancer patients, symptomatic, asymptomatic and treated and untreated.

In this study, 52 out of 116 patients had metastatic lesions detected by bone scan. Among the 52 patients, majority $(57.7 \%)$ patients had rib as metastatic site. Hip bone and lumbar vertebra had same frequency $(32.7 \%)$ as metastatic site followed by thoracic vertebra (26.9\%), then sternum and skull (23.1\%). 
Rusu, et al. (2004) found the higher frequency of metastasis was in the vertebral column, then the pelvis, rib and sternum (7). Similarly Fallahi, et al. (2011) reported the most common sites of skeletal metastases in the different types of cancer were vertebral column, pelvis, sternum and rib, respectively (8). These findings were in disagreement with the current study may be due to variation in the type of cancer and number of patients.

In this current study, it was observed that among asymptomatic carcinoma breast patients $21.7 \%$ patients had positive bone scan for metastatic disease. Fallahi, et al. (2011) found 58.5\% of patients with bone metastasis due to breast cancer reported no localized bone pain which was higher than the current study (8). This current study also revealed that 20(66.7\%) out of 30 asymptomatic carcinoma prostate patients found positive for bone metastases detected by bone scan. Fallahi, et al. (2011) found no significant association between the site of bone metastases and location of the pain perception in most of the skeletal zones in the subgroup with prostate cancer (8). Moslehi, et al. (2012) found out of 203 asymptomatic patients with prostate cancer, 55 cases $(27.1 \%)$ had bone metastasis which was lower than the current study (9). Levren, et al. (2011) examined the relationship between bone pain and metastases in a group of patients with prostate or breast cancers (10). They found that $47 \%$ (18 out of 38) patients with prostate cancer with pain and $12 \%$ (2 out of 17) patients without pain had metastasis. On the other hand, in the subgroup of breast cancer, $71 \%$ of the asymptomatic patients had metastasis and $34 \%$ of the patients with pain had metastases. They concluded that there was a significant association between pain and skeletal metastases in patients with prostate cancer and a reverse relationship in patients with breast cancer (10). But in this current study prostate cancer patients without pain had higher frequency of metastatic bone disease detected by bone scan than the patients of breast cancer without pain. In the subgroup with lung cancer, in this study it was observed that among 12 patients, $8(66.7 \%)$ patients had positive bone scan. Shinto, et al. (2009) found skeletal metastases in 13 patients (14.13\%) out of 92 asymptomatic lung cancer patients; percentage was lower than the current study (11). Ursavas, et al. (2007) reported bone metastases in 21(52.5\%) of 40 symptomatic non-small cell lung cancer patients and $12(18.18 \%)$ of 66 asymptomatic patients (12). Similarly Erturan, et al. (2005) noticed bone metastases in $21(53 \%)$ of 39 symptomatic non-small cell lung cancer patients, $5(5.8 \%)$ of 86 asymptomatic patients (13). These findings were in disagreement with the current study may be due to insufficient number of cases and inclusion of all types of lung cancer in the current study.

Limitations of the study are that the study population was selected from one tertiary referring hospital in Dhaka city, so that the results of the study may not reflect the exact incidence of the country and the present study was conducted at a very short period of time. Small sample size was also a limitation of the present study.

In future, multicentre study may be done and further studies may be undertaken by including large number of patients. Bone scintigraphy may be done in newly diagnosed asymptomatic cancer patients as baseline investigation for the initial staging of disease and proper management of patients.

\section{CONCLUSION}

Bone scan finding was positive in $44.8 \%$ newly diagnosed asymptomatic cancer patients. Among the most common two types of cancer, frequency of skeletal metastatic lesion detected by bone scan was higher in asymptomatic prostate cancer patients than asymptomatic breast cancer patients, but skeletal metastatic lesion was found in almost all type of cancer patients without metastatic symptoms. It may be concluded from the results of present study that newly diagnosed asymptomatic cancer patients are frequently associated with metastatic bone disease, those can be detected by bone scintigraphy. Clinicians may consider bone scan as baseline investigation in the asymptomatic cancer patients for initial staging and planning for treatment.

\section{REFERENCES}

1. Hussain SA and Sullivan R. Cancer Control in Bangladesh. Jpn J Clin Oncol 2013;43(12):1159-69.

2. O’Sullivan GJ, Carty FL and Cronin CG. Imaging of bone metastasis: An update. World J Radiol 2015;7(8):202-11. 
3. Joyce MJ,May, 2012. Metastatic Bone Tumors. Retrieved from MSD Manual Website: http://www.msdmanuals.com/

4. Coleman RE. Clinical features of metastatic bone disease and risk of skeletal morbidity. Clin Cancer Res 2006;12(suppl. 20):6243-49.

5. Love C, Din AS, Tomas MB, Kalapparambath TP and Palestro CF. Radionuclide Bone Imaging: An Illustrative Review. RadioGraphics 2003;23(2):341-58.

6. Embati RAK. Assesing utility of Tc-99m MDP bone scan in symptomatic versus non-symptomatic cases of cancer at Nuclear Medicine Unit, at Mulago National Referral Hospital. In: International Conference on Clinical PET-CT and Molecular Imaging (IPET 2015): PET-CT in the Era of Multimodality Imaging and Image-Guided Therapy, 5 - 9 October 2015, IAEA Headquarters, Vienna, Austria.

7. Rusu V, Boiculese LV, Stefanescu C, Hountis D and Costin, M. A retrospective study of bone metastases distribution on 420 whole body scans. Rev Med Chir Soc Med Nat Iasi 2004;108(1):114-17.

8. Fallahi B, Beiki D, Khodaparast MB, Gholamrezanezhad A, FardEsfahani $\mathrm{A}$ and Eftekhari M. Additive clinical value of bone scintigraphy in patients with malignant tumors with absence of localized bone pain: A report on most common sex-related cancers. Iran J Nucl Med 2011;19(1):51-58.

9. Moslehi M, Cheki M, Salehi-Marzijarani M, Amuchastegui T and Gholamrezanezhad A. Predictors of bone metastasis in pre-treatment staging of asymptomatic treatment-naïve patients with prostate cancer. Rev Esp Med Nucl Imagen Mol 2013;32(5):286-89.

10. Levren G, Sadik M, Gjertsson P, Lomsky M, Michanek A and Edenbrandt L. Relation between pain and skeletal metastasis in patients with prostate or breast cancer. Clin Physiol Funct Imaging 2011;31(3):193-95.

11. Shinto A, Pachen L, STK and Joseph C. Skeletal metastases in apparently operable lung cancer evaluated with whole body bone scan- A pilot study in south India. The Internet Journal of Thoracic and Cardiovascular Surgery 2009;14(2).

12. Ursavas A, Karadag M, Uzaslan E, Rodoplu E, Demirdögen E, Burgazlioglu B et al. Can clinical factors be determinants of bone metastases in non-small cell lung cancer? Annals of Thoracic Medicine 2007;2(1):9-13.

13. Erturan S, Yaman M, Aydin G, Uzel I, Müsellim B and Kaynak K. The role of whole-body bone scanning and clinical factors in detecting bone metastases in patients with non-small cell lung cancer Chest 2005;127(2):449-54. 